\title{
Resonant Mode Controllers for Launch Vehicle Applications
}

Ken E. Schreiner

General Dynamics

San Diego, California

and

Mary Ellen Roth

Lewis Research Center

Cleveland, Ohio

Prepared for the

Applied Power Electronics Conference and Exposition

sponsored by the Institute of Electrical and Electronics Engineers

Boston, Massachusetts, February 23-27, 1992 
a low inertia, high frequency induction motor to decrease motor size and to decrease the power needed for acceleration, 3 ) a field oriented induction machine controller for high performance servo control and, 4) bipolar lithium thionyl chloride batteries for increased energy density and decreased system weight.

\section{PULSE DENSITY MODULATED CONVERTERS}

The standard technique for producing a converter is the pulse width modulated (PWM) approach. This type of converter operates from a dc bus or from a rectified ac source. The switches in each phase of the three phase half-bridge configuration are switched to produce the output waveform as shown in figure 1 . The width of each of the pulses is changed to vary the voltage and frequency. While the infinitely varlable on and off times would theoretically give better current regulator performance, the switching speed limitations of a switched mode converter significantly degrade the regulator performance.

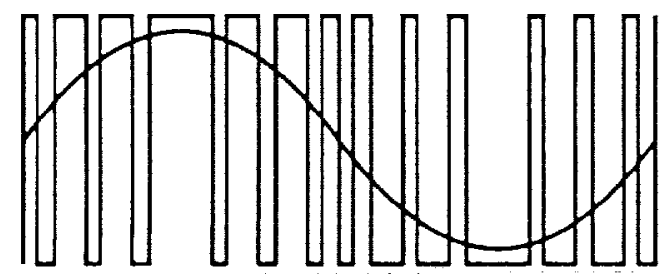

Fig 1. Pulse width modulation regulation

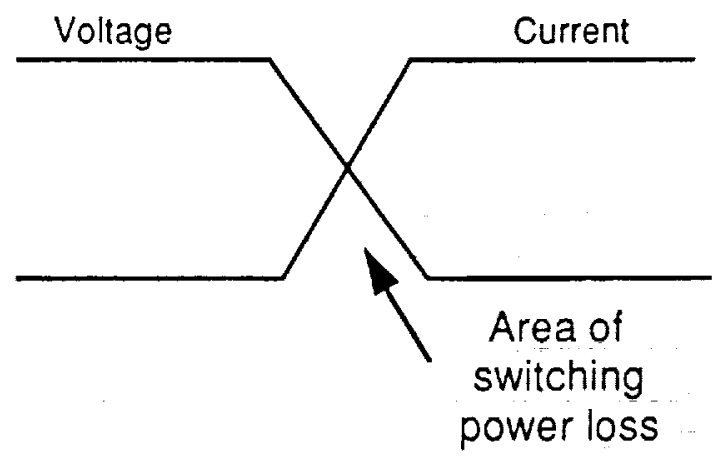

Fig 2. Switching power loss in hard switched converter
The switches in the PWM converter, operating from a dc source, must switch from the high voltage off condition to the low voltage, high current on condition, as shown in figure 2 . This switching results in power loss and voltage stress on the switches. This voltage stress must be controlled by lossy snubbers. With today's components, the switching speed is limited by the losses and stress to the $2.5 \mathrm{kHz}$ range for a high powered converter.

The controllers described in this paper use a pulse density modulated(PDM) design approach $[1,4]$. The input to the PDM converter is a high frequency ac bus or a $d c$ bus. Both of the resonant converters operate by steering each pulse of the input waveform to the low frequency output. The output voltage waveform of the converter is shown in figure 3.

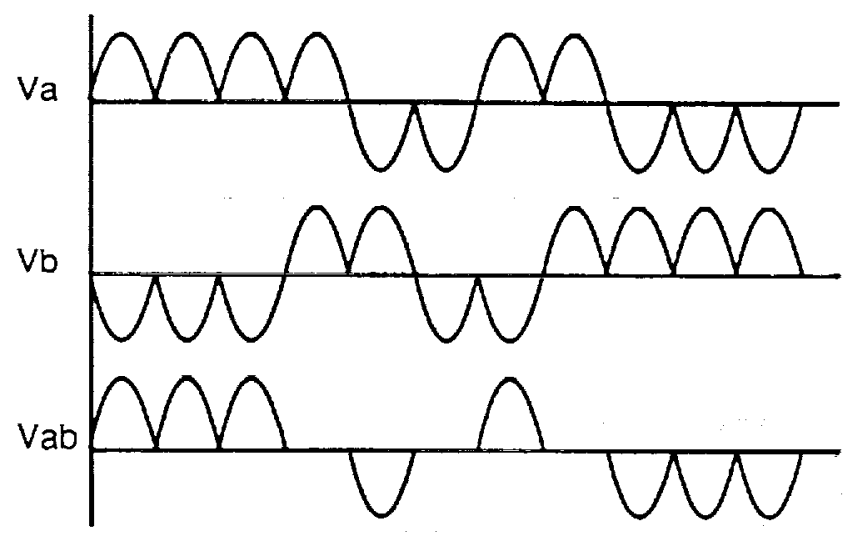

Fig 3. Pulse density modulation regulation

In the PDM converter, all the switching takes place at the zero voltage crossing of the input voltage waveform. Zero voltage switching results in negligible switch stress and switching loss since the voltage is zero during the time that the current is switching between devices. The switching trajectories of the resonant and switched mode converters, shown in figure 4, clearly indicate the reduced stress to the switching devices in the resonant mode controller. Due to the zero voltage switching, the PDM converter does not have the lossy snubbers that are associated with the PWM converters.

The switching devices used in a PDM controller are similar to the types used in a PWM controller, but because of the reduced stress and switching loss, 


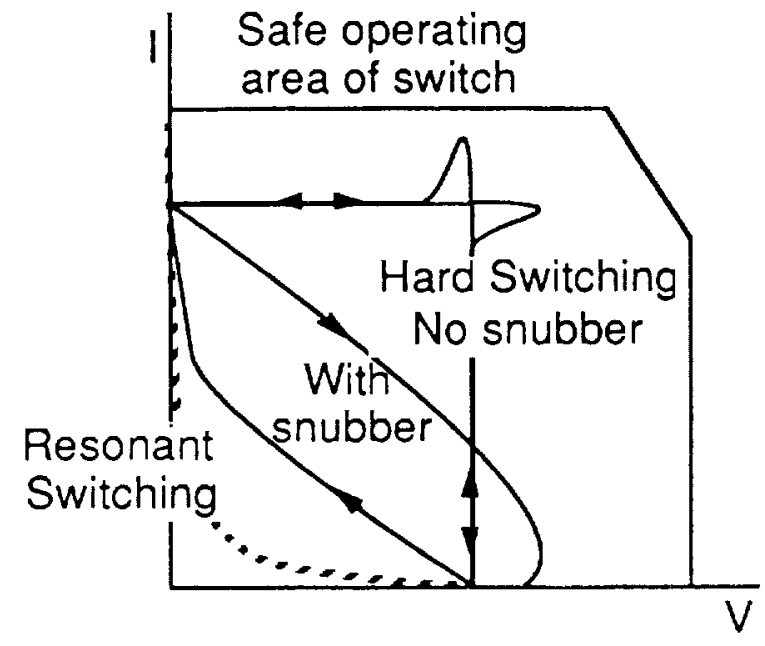

Fig 4. Switching trajectories in switched mode and resonant converters

they can be operated at a much higher frequency. The switches used in this EMA application are IGBTs, which have 2 usec turn off times. Similar devices with similar ratings are limited to approximately $5 \mathrm{kHz}$ in a PWM converter while the same devices are being used in a $40 \mathrm{kHz}$ resonant system.

\section{A. HIGH FREQUENCY AC BUS CONTROLLER}

In applications where there are many controllers with limited, uncorrelated power requirements, use of a high frequency resonant ac bus to each of the controllers may offer significant power and weight benefits. In this system, resonant inverters generate a single phase ac voltage. By managing the loads and source inverters, the system can be operated at the optimal efficiency point. The high frequency ac system also has advantages in redundancy management and voltage level shifting.

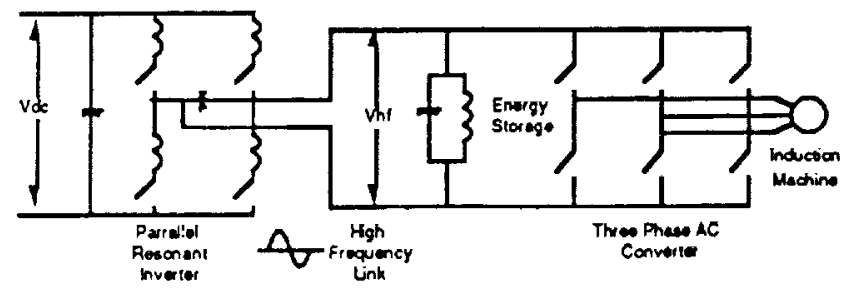

Fig 5. High frequency ac bus motor controller

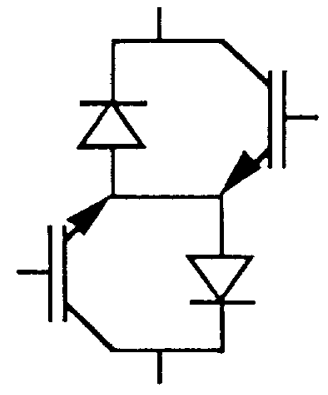

Figure 6. Bidirectional switch configuration

In the high frequency ac system of figure 5 , energy from the dc source on the vehicle must be first converted to a $20 \mathrm{kHz}$ single phase link. This is done by using a Parallel Output Series Resonant (POSR) converter[5]. This type of inverter has inherent bidirectional power capability and performs all switching at zero current, resulting in low losses at large loads. By maintaining the resonant inverters near full load, resulting in over $95 \%$ efficiency, weight and size of the overall system is reduced. This bus is then connected to all controllers.

The bridge circuit in the motor controller performs the switching function by simply selecting a new switch position at each of the voltage zero crossings. There is no switching loss and since there are no snubbers, there is no snubber loss. The high frequency ac bus converter also uses bidirectional switches, achieved by placing the switches in parallel, with blocking diodes in series with each switch, as shown in figure 6 .

\section{B. DEDICATED CONTROLLER}

In applications where load management would not be possible or large peak power is required, dedicated controllers running off a dc source would be used. In a system that requires dedicated power conversion, low switching losses and high frequency switching in the power stage are necessary.

In this application a Resonant DC Link converter [6] would provide lossless switching and high frequency operation. This converter uses a three phase half bridge topology with the addition of an inductor and capacitor to form the resonant elements, as shown in figure 7 . The resonant conversion is performed by turning on all of the controller switches which shorts the resonant capacitor, and then 


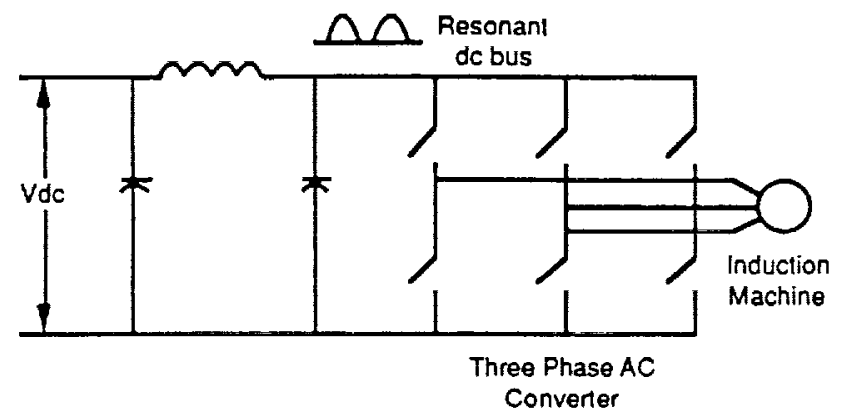

Fig 7. Resonant dc motor controller

allowing the resonant inductor current to reach a set level. One switch in each of the phases is then released, allowing the voltage to rise and then resonate back to zero, where the cycle is then restarted. Since the bus voltage always returns to zero, switching loss is eliminated. Switching frequencles of $60-100 \mathrm{kHz}$ can easily be obtained with this circuit topology.

\section{INDUCTION MOTOR}

The induction motor is a robust machine capable of much abuse while offering some important control advantages. The induction motor field is energized from the stator windings and therefore preferred in redundant applications where a failed motor with an internally provided field, such as a permanent magnet motor, would become a load on the system. Also the induction machine is capable of increased speed with reduced field operation which is not practical in a permanent magnet motor. While the permanent magnet motor will run more efficiently at a given operating point, the extreme variation in loads and power required for a launch vehicle actuator makes the losses in the two motors approximately the same.

For this application, the stator frequency has been increased to $800 \mathrm{~Hz}$ to decrease the size and inertia of the motor. The rotor has also been optimized for low inertia and low losses. The resulting motor that has been designed by Sundstrand is rated for a peak of $70 \mathrm{HP}$ while weighing only 20 pounds.

\section{MOTOR CONTROL}

For good torque control over the speed range from zero to full rated speed, an indirect field oriented



Fig 8. Field Oriented Controller

controller using a PI speed regulation loop is used, as shown in figure 8 . Proper orientation of the motor flux is achieved by maintaining the correct slip angle. The incremental slip angle is added to the rotor angle to generate the proper stator phase relationship. The magnitude of the reference current is determined from the rotating 2 axis components - Id and Iq. Id is the flux producing component of the current and lq. which is at right angles with the flux, produces the torque component. A two axis rotating frame to three axis stationary frame transformation is then performed to generate the reference phase currents.

\section{A. REGULATION}

The discrete nature of the resonant converter waveforms make the use of the PWM regulation techniques unusable. The delta modulator, which is a sampled data regulator, is ideal for regulation in a resonant type converter. The PDM controller in this paper uses a modified delta modulator to regulate the molor current[2,3], as shown in figure 9 . Since the voltage to the windings occurs at discrete times, the delta modulator regulator is used to select the near optimal switch states at each switching instant from

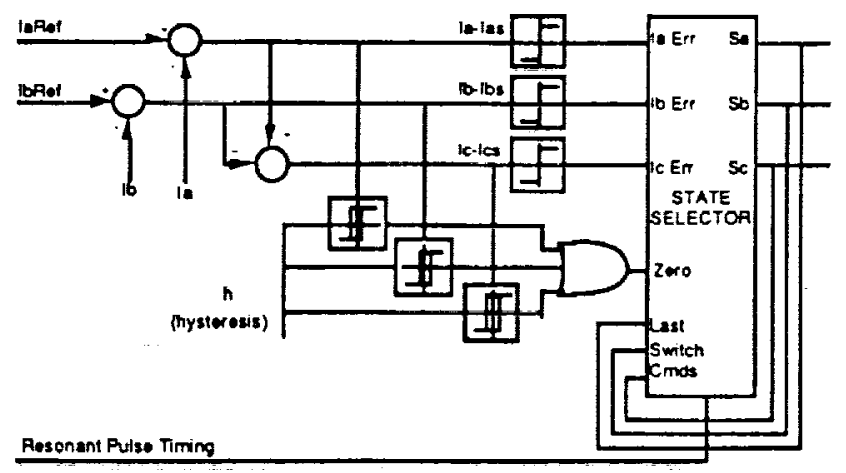

Fig 9. Modified Delta Modulation Regulator 
the set of possible voltage vectors shown in figure 10 . While a discrete regulator cannot offer the performance of a continuously variable regulator operating at the same switching frequency, the increase in switching frequency due to resonant switching offers much better current regulation.



Fig 10 Possible Voltage Vectors

Current regulation is performed by sampling current error polarity at the resonant voltage crossing. The magnitude of the current error is then measured to see if it is within a hysteresis band around the current reference, in which case zero line-to-line voltage is applied to the motor windings. If a zero stale is not selected, the next switching state is selected from the current error polarities and the previous switch states.
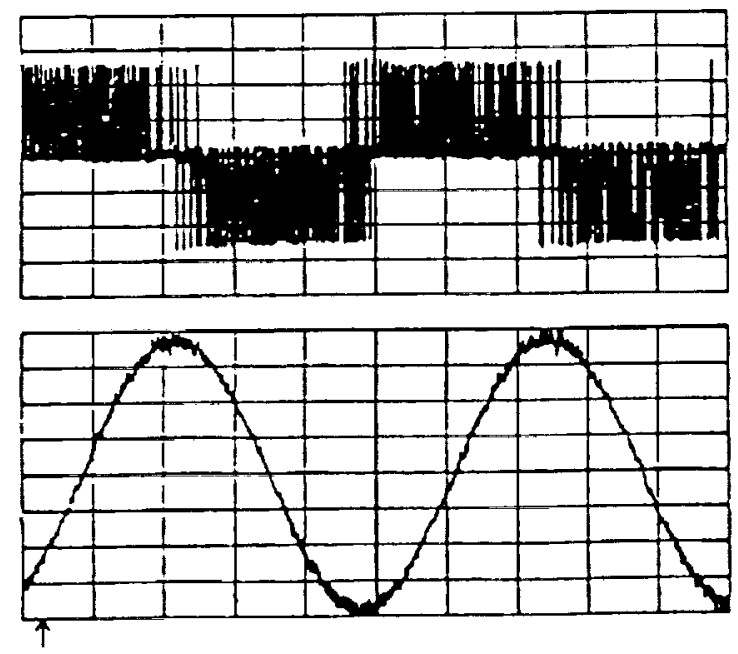

Fig 11. Experimental waveforms for current regulator. Top trace: Line voltage(100V/div). Bottom Trace: Line current(10Adiv).

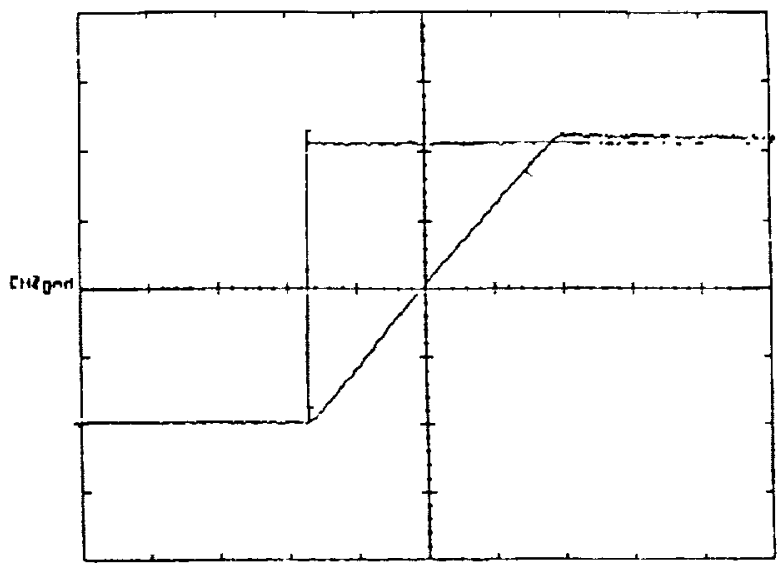

Fig 12. Response of the Controller to a 5000RPM Step Command(100msec/div). Top trace: Step Command. Bottom Trace: Speed Feedback.

\section{LITHIUM BATTERY}

An EMA application for launch vehicles requires a power source that can supply high discharge rates while being relatively small. The typical criteria for selecting a battery, the amp hour rating, is usually not important for a 10-20 minute flight. Current technologies, such as silver zinc, have high amp-hour ratings but need to be large to supply the high discharge rates. An estimate of the weight of a silver zinc battery for this application is 275 pounds.

Currently, Yardney Technical Products and others are developing bipolar lithium thionyl chloride batteries for high discharge rate applications. This battery has been shown, using single cell test data, to be capable of the required discharge rates with approximately ten times the required battery capacity. Battery size is approx. 10 inches in diameter and 8 inches high for the required 80 cell stack, with a baltery weight of only 40 pounds. 


\section{SYSTEM IMPROVEMENTS}

The second system that is now being built uses the $d c$ resonant approach. Switching frequency of this controller will be $>60 \mathrm{kHz}$. Full digital control of the motor and resonant conversion will be provided by a processor (DSP) while the actuator position control will be provided by a state variable regulator. Also included in the controller will be acceleration feedback for active damping of system resonances and response to impact loads such as engine start.

A linear actuator for this system is being built by MOOG and testing of the complete system will be performed on their Space Transportation System (STS) test fixture. The actuator is designed to meet the NLS main engine thrust vector control requirements which are very similar to the STS main engine actuator requirements.

\section{CONCLUSION}

By using advanced technologies, it is now practical to incorporate electrically operated actuators in place of high power hydraulically operated acluators. Lossless switching, decreased battery size, efficient motors, and improved control electronics have all lead to the decreased size and weight of an EMA system.

The use of resonant topologies has resulted in a dramatic increase in switching frequencies while also decreasing power requirements and thermal loads. The ac resonant bus system offers high efficiency, redundant operation, and high switching frequencies for avionic systems with multiple load applications. The dc resonant link offers low losses and high frequency operation for high power, low duty cycle applications.

Induction molors have always been widely used, robust machines, but the lack of high performance control electronics has slowed their use in servo applications. The induction machine, when linked with a high performance field oriented controller, is an ideal motor candidate for actuator applications when redundant operation and hostile environment operation are required.
Lithium thionyl batteries have been shown to offer the high discharge rates required by a high power EMA system with a decrease in power source weight by up to $80 \%$.

\section{REFERENCES}

1. P. K. Sood and T. A. Lipo, Study of the Generator/Motor Operation in a High Frequency Link Space Power System, NASA Report, Contract No. NAG3-631.

2. T. G. Habetler and D. M. Divan, Performance Characterization of a New Discrete Pulse Modulated Current Regulator, IEEE Tran. Ind. Appl., vol. IA-25, no. 6. pp 1139-1148, Nov./Dec., 1989.

3. R. D. Lorenz and D. M. Divan, Dynamic Analysis and Experimental Evaluation of Delta Modulators for Field Oriented AC Machine Current Regulators, 1987 IEEE Ind. Appl. Soc. Conf. Rec., pp 196-201.

4. S. K. Sul and T. A. Lipo, Field Oriented Control of an Induction Machine in a High Frequency Link Power System. Power Electronics Specialist's Conference, April 1988, pp 1084-1090.

5. N. Mapham, An SCR Inverter with Good Regulation and Sine-wave Output, IEEE Tran. Ind. Gen. Appl., vol. IGA-3, pp 176-187, Mar/Apr., 1967.

6. D. M. Divan, The Resonant DC Link Converter - A New Concept in Static Power Conversion, IEEE Tran. Ind. Appl., vol. 25, no. 2, pp 317-325, Mar./Apr.., 1989. 
(ב-

.




\begin{tabular}{|l|c|r|}
\hline 1. AGENCY USE ONLY (Leave blank) & $\begin{array}{c}\text { 2. REPORT DATE } \\
1992\end{array}$ & $\begin{array}{r}\text { 3. AEPORT TYPE AND DATES COVERED } \\
\text { Technical Memorandum }\end{array}$ \\
\hline
\end{tabular}

4. TITLE AND SUBTITLE

5. FUNDING NUMBERS

Resonant Mode Controllers for Launch Vehicle Applications

6. AUTHOR(S)

WU-946-02-2E

Ken E. Schreiner and Mary Ellen Roth

7. PERFORMING ORGANIZATION NAME(S) AND ADDRESS(ES)

8. PERFORMING ORGANIZATION REPORT NUMBER

National Aeronautics and Space Administration

Lewis Research Center

Cleveland, Ohio 44135-3191

E- 6887

9. SPONSORING/MONITORING AGENCY NAMES(S) AND ADDRESS(ES)

10. SPONSORING/MONITORING AGENCY REPORT NUMBER

National Aeronautics and Space Administration

Washington, D.C. 20546-0001

NASA TM -105563

\section{SUPPLEMENTARY NOTES}

Prepared for the Applied Power Electronics Conference and Exposition sponsored by the Institute of Electrical and Electronics Engineers, Boston, Massachusetts, February 23-27, 1992. Kenneth E. Schreiner, General Dynamics Space Systems Division, San Diego, California 92129. Mary Ellen Roth, NASA Lewis Research Center. Responsible person, Mary Ellen Roth, (216) 433-8061.

12a. DISTRIBUTIONAVAILABILITY STATEMENT

12b. DISTRIBUTION CODE

Unclassified - Unlimited

Subject Category 15

\section{ABSTRACT (Maxlmum 200 words)}

Electro-mechanical actuator (EMA) systems are currently being investigated for the National Launch System (NLS) as a replacement for hydraulic actuators due to the large amount of manpower and support hardware required to maintain the hydraulic systems. EMA systems in weight sensitive applications, such as launch vehicles, have been limited to around $5 \mathrm{hp}$ due to system size, controller efficiency, thermal management, and battery size. This paper presents design and test data for an EMA system that competes favorably in weight and is superior in maintainability to the hydraulic system. An EMA system uses dc power provided by a high energy density bipolar lithium thionyl chloride battery, with power conversion performed by low loss resonant topologies, and a high efficiency induction motor controlled with a high performance field oriented controller to drive a linear actuator.

14. SUBJECT TERMS

Resonant mode; Controllers; Electromechanical actuation

16. PRICE CODE

17. SECURITY CLASSIFICATION OF REPORT

Unclassified
18. SECURITY CLASSIFICATION OF THIS PAGE

Unclassified
19. SECURITY CLASSIFICATION OF ABSTRACT Unclassified 